\title{
Elderly after a Disaster: Not Only Victims but also Resilient People
}

\author{
Danielle Maltais* \\ Department of Human and Social Sciences, University of Quebec in Chicoutimi, Canada
}

*Corresponding author: Danielle Maltais, Department of Human and Social Sciences, University of Quebec in Chicoutimi, Quebec, Canada.

To Cite This Article: Danielle Maltais, Elderly after a Disaster: Not Only Victims but also Resilient People. 2020 - 8(3). AJBSR.MS.ID.001262. DOI: 10.34297 /AJBSR.2020.08.001262

Received: 眥 March 02, 2020; Published: 眥 March 19, 2020

\begin{abstract}
During the last 20 years, It was possible to see that the most of the inventoried studies concerning senior citizens in the field of disasters, deal with the frequency of psychological problems like post-traumatic stress, anxiety or depression arising after being expose to a disaster [1-6]. Other research looks at the relationship between perceived and received social support and the post-disaster health of senior citizens [2,7,8]. A limited number of researchers deal with the resiliency process of which senior citizens are a part of during disruptive events as well as the positive and negative impacts on personal values and beliefs of senior citizens [9].

At the same time, our research team realized different quantitative, qualitative or mixt studies about the impacts of disaster on the health of elderly two, three or height years after floods, two years after ice storm or three years after a train derailment [10-12]. Despite the presence of physical and psychological health problems with elderly victims of flood, ice storm or train derailment that we meet, many of them have identified positive aspects from their experience at a spiritual level and to their personal values. Some positive changes were noted by the senior citizens at different measured times. They can be regrouping in six large themes:
\end{abstract}

\section{Confidence or Optimism Toward the Future}

Many elderlies mentioned feeling more optimistic toward the future, because the disaster allowed them to realize that local and extra-territorial solidarity can manifest themselves in these circumstances. They now believe they will get help when in difficulty. Even if they say they're confident towards what the future holds, those who answered noted that they grant less importance to their financial situation than before and that they take things much more lightly, day by day, without too much planning or project elaboration.

\section{Personal Safety Feeling}

A few of those who answered felt safer because they relocated farther from the water's edge or because they were living in a new home in spite of feeling a greater vulnerability in relation to the elements of nature and of feeling less secure, fearing more and stronger natural disasters.

\section{Personal Growth}

A good number of senior citizens think that their level of selfesteem grew because they realized the pertinence of the choices and the options, they favored during the disaster and during the recovery phase. A few of those who answered our questions noted they had a better self-esteem because many times, they had to insist on their rights with different people and those in authority and show tenacity. The ability to express oneself is also an aspect that some have admitted having gotten out of the experience. Some elderly has also stated granting less importance to other people's opinion and displaying more determination in the elaboration of their projects.

Many victims consider themselves better equipped to react to a possible disaster and evoke the fact that having lived through such a test has brought them a feeling of competence underestimated 
until now. The diminishing of prejudice, the sensitivity towards difficulties others have survived through, the increased openmindedness and empathy are also aspects associated to personal growth. Certain participants also said that their exposition to a disaster brought them to discover personal resources (autonomy, resourcefulness, etc.) they did not know they had. Many of those who answered believe they will be able to use the resources at their disposal more efficiently if a similar event arises.

\section{Spirituality}

In general, the religious beliefs or spiritual values stayed the same. However, many of the interviewed elderly mentioned that their beliefs in God helped them face the hardships.

\section{Questioning Personal Values}

A few elderly evoked that the losses or the damage they suffered led them to a deep consideration on the importance granted to material things, even if it demands a certain effort. Many of the interviewed elderly also stated that their priorities have changed, and they now grant more importance to their conjugal and family relationships and by being more sensitive to the hardship's others may have to deal with in their lives. Many have noted a reconciliation, a better understanding and a strengthening of the ties between spouses and the other members of their entourage. The hardships lived at the human relationship level in the first months following the disaster, because of the different stresses then, made way for deeper feelings, a better comprehension and communication as well as an undeniable mutual support.

\section{Acceptance of Outside Help}

Among the interviewed elderly people, many mentioned having learned how to ask for help and to accept to receive help from their immediate surroundings but also from others, including the help offered by paid workers and volunteers. Moreover, these people also noted that they show more availability to help those individuals with problems.

\section{Conclusion}

Our different studies we realized with the elderly have allowed us to note that natural or technological disaster victims may notice a deterioration of their health, that they are susceptible of experiencing positive changes to their beliefs and personal values. In spite of the differences of opinion between the researchers concerning elderly people's capacity to overcome the different stresses linked to the exposure to a disaster, we find in different disaster contexts, that the elderly have shown resilience in spite of the negative repercussions these events had on their psychological and physical health. In spite of their material losses and their physical and psychological problems, the varied stresses they experienced and the temporary modification to their lifestyles have been able to note that unsuspected qualities and strengths are within them and will enable them to resolve their problems and defend their interests with the authorities that are sometimes refractory to the victim's needs. Elderly are not only victims in case of disaster, but they are also people able to identify positive aspects on their life after their exposition of this kind of event.

\section{References}

1. Brockie L, Miller E (2017) Older adults' disaster lifecycle experience of the 2011 and 2013 Queensland floods. International J Disast Risk Reduc 22: 211-218.

2. Flagg JA (2017) The social consequences of a natural/technological disaster: evidence from Louisiana and Mississippi. Local Environment 22(3): 306-320.

3. Inoue M, Yamaoka K (2017) Social factors associated with psychological distress and health problems among elderly members of a disasteraffected population: Subgroup analysis of a 1-year post-disaster survey in Ishinomaki area, Japan. Disast Medic Public Healt Prepared 11(1): 6471.

4. Lancaster SL, Melka SE, Rodriguez BF (2011) Emotional predictors of PTSD symptoms. Psycholo Trau: Theory Research Practice Policy 3(4): 313-317.

5. Hoeksema NS, Aldao A (2011) Gender and age differences in emotion regulation strategies and their relationship to depressive symptoms. Personal Individ Differen 51(6): 704-708.

6. Soonthornchaiya R, Tuicomepee A, Romano JL (2018) Impacts of Tsunami Disaster in Thai Elderly Survivors. Ageing Internat 44: 1-16.

7. Galea S, Tracy M, Norris F, Coffey SF (2008) Financial and social circumstances and the incidence and course of PTSD in Mississippi during the first two years after Hurricane Katrina. J Traumat Stress 21(4): 357-368.

8. Labra O, Maltais D, Gingras LG (2018) Medium-term health of seniors following exposure to a natural disaster. Inquiry 55: 1-11.

9. Chung MC, Werrett J, Farmer S, Easthope Y, Chung C (2000) Responses to traumatic stress among community residents exposed to a train collision. Stress Medicine 16(1): 17-25.

10. Maltais D (2013) Post-trauma and the elderly: when vulnerability and the contribution of the elderly go hand in hand. Grotius Internat Germany.

11. Maltais D, Simard A, Robichaud S (2002) The consequences of the ice storm in the elderly based on accommodation strategies. In: Maltais D (Ed.), Disasters and health status of individuals, workers and communities, Chicoutimi GRIR-UQAC, USA pp. 321-334.

12. Maltais D, Tremblay AJ, Labra O, Fortin G, Généreux M, et al. (2019) Seniors' who experiences the Lac-Mégantic train derailment tragedy: What are the consequences on physical and mental health? Gerontology Geriatric Medec 5: 1-8. 